\title{
Intuition as Design Dialogue: Discovering a Language beyond Words
}

\author{
Randall Teal University of I daho
}

\begin{abstract}
Henri Bergson considered the truest form of knowing to be attainable only through acts of intuition, as he believed the intuitive state created a direct connection to reality itself. For architecture, a field that is grounded in experience, it is important to balance the drive of the intellect with intuitive strategies, which help move toward the unification of data under an experiential aegis. Drawing primarily upon the writings of Bergson and Martin Heidegger, this paper describes how the reductive proclivities of the intellect tend to obscure the embodied insights of intuition, and how the listening response of intuition reveals a primal language that is activated by the immersed dialogue of one experiencing the world.
\end{abstract}

\section{I ntroduction}

...it is not the case that by means of likeness a finite intellect can attain the truth about things. For truth is not something more or less, but something indivisible. Whatever is not truth cannot measure the truth precisely ... Hence the intellect, which is not truth, never comprehends truth ...1

|nikolous cusanus|

The Western educational system since the enlightenment has generally aimed toward creating problem solvers and answer finders, but has remained limited in the cultivation of ability with measures outside the intellectual realm. Architectural education is a rarity that straddles a zone between intellect and intuition. However it too often falls prey to intellectual biases. Although understanding codes, environmental controls, construction, etc. are all essential to the practice of architecture, these intellectual skills form only part of the picture. Yes - buildings must stand up; yes buildings must keep weather out; and yes - buildings must accommodate real needs; but these things alone are not architecture.
The heart of architecture lies in the vicissitudes of embodied experience and the pursuit of it asks that one work with experience and feeling in a participatory manner. This engagement begins an understanding that infuses new work with energy and mystery. However, capturing the intangible qualities of the experiential and proceeding toward great moments of architecture necessarily requires a confrontation with ambiguity and the risk of the unknown as this acknowledges situational specificity. By proceeding in the face of the unknown a creator engages in dialogue with that which is becoming.

Intuition is one name given the human capacity to participate in this process of becoming. Intuition touches upon things that are inaccessible to the intellect and interprets them through its activated flow. In order to enter this flow in architecture, design must be undertaken with both courage and freedom; in this way intuition is allowed to participate within the uncertainty of becoming and stimulate currents of significance. The communication of intuition speaks silently through revealing and disclosing. Partaking in this dialogue demands that one genuinely recognize, as Martin Heidegger describes, "this speaking that listens and accepts is responding."2 In other words, intuitive dialogue connects us to our very capacity for not knowing and allows a tarrying in the specific uncertainty of a situation. For Heidegger, "language is the house of being," 3 and, "speaking about language almost inevitably turns it into an object." In other words, language is the significance of situation and in order for the "saying" of language to bring intelligibility to one's dealings in the world one must first and foremost dwell in language. The listening of intuition hears this saying of language by enacting it and in so doing affords the world an opportunity to speak. In design when we let the world speak our architecture becomes both articulate and significant.

\section{The Hearing of I ntuition}

French philosopher Henri Bergson believed intuition to be the true method for understanding, occurring when one 
lives in the world with intimacy. ${ }^{5}$ Intuition arises with a response to the call of spontaneous engagement which allows focus, absorption, and subsequently insight. For Bergson this insight is not possible from the perspective of mere observer or through reflection as he says the intuitive communicates, "an external reality which is given immediately to our mind." ${ }^{\prime \prime}$ With a concern similar to that seen in Heidegger's comment about the danger of language becoming an object, Bergson understands that when an experience is mediated by reflection, there emerges a rift between subject and object; the separation of reflection ensures that one does not experience the reality as one remains outside of an encounter by way of their observations. Bergson describes the difference between the two kinds of knowing in his essay, "An Introduction to Metaphysics":

Take, for example, the movement of an object in space. I perceive it differently according to the point of view from which I look at it, whether from that of mobility or immobility. I express it differently, furthermore as I relate it to the system of axes or reference points, that is to say, according to the symbols by which I translate it. And I call it relative for this double reason: in either case, I place myself outside the object itself. When I speak of absolute movement, it means that I attribute to the mobile an inner being and, as it were, states of soul; it also means that I am in harmony with these states and enter into them by an effort of imagination. Therefore, according to whether the object is mobile or immobile, whether it adopts one movement or another, I shall not have the same feeling about it. ${ }^{7}$

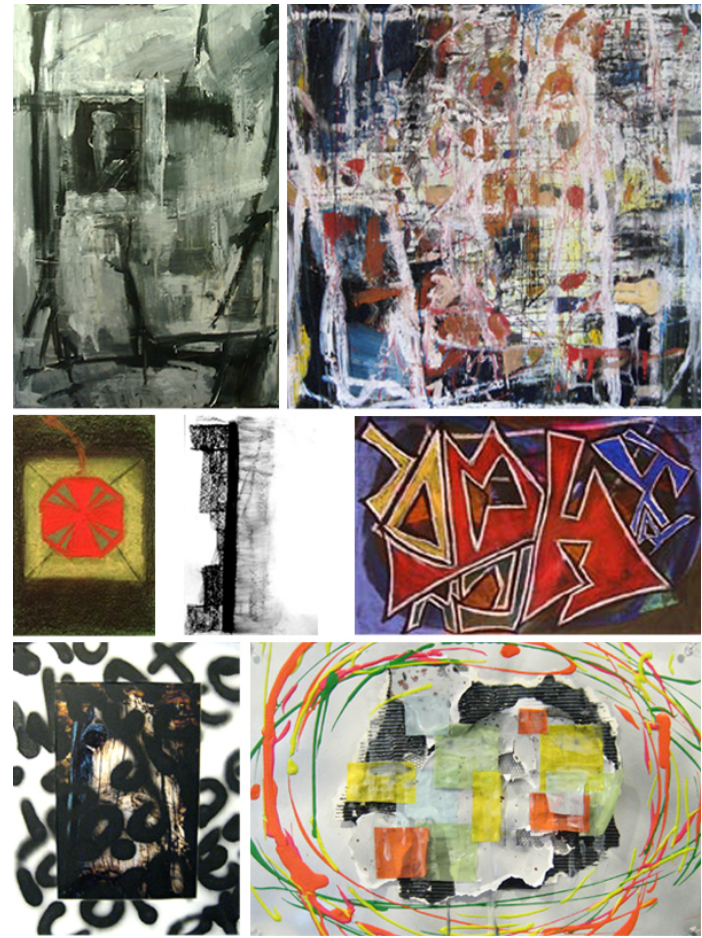

Figure 1: Engaging movement and mood through imagination. ${ }^{8}$

So it is this ability to adopt movement through the "effort of imagination" that characterizes in part the difference between the intellectual perspective and the intuitive for Bergson (Fig. 1). Now as Bergson and Heidegger are attempting to avoid the subject/object dichotomy, I do not mean to suggest that intellect and intuition are oppositional or should be thought of as a binary. In fact, the process of design depends upon the inseparability of the two. Ironically, the relative indefinability of intuition often allows it to be veiled by the more palpable presence of the intellect. In this way, the intellect tends to segregate or obfuscate intuition, which leads this discussion to perhaps over-stress intuition so as to help shed light on both the importance of intuition and some of the reasons for the dichotomy that arises between intuition and intellect. The requirement for imagination of which Bergson speaks is one of the reasons that the intellect becomes suspicious of intuition in that for the rational mind intuition appears to lack any real grounds. Heidegger has suggested that part of what is coming into play here is a poor understanding of those modes of behavior which are not rooted in the rational. He sees these misconceptions and the corresponding over-valuation of the rational being perpetuated by viewpoints and translations in 
the history of Western thought, which have misunderstood more previously nuanced conceptions. ${ }^{9}$ Offering an alternative stance on the way we encounter the world he says,

Perhaps however what we call a feeling or a mood, here and in similar instances, is more reasonable -that is, more intelligently perceptive - because more open to being than all that reason which, having meanwhile become ratio, was misinterpreted as being rational. ${ }^{10}$

Heidegger takes the rational to be a derivative mode of other more involved ways of knowing and Bergson too thinks the intellect's limitation is that it has a tendency to take up things beyond its real purview. In this way it suppresses other vital attributes of our perceptive faculties. Bergson explains that intuition is not something mystical or irrational and in fact is quite important:

There is nothing mysterious about this faculty. Whoever has worked successfully at literary composition well knows that when the subject has been studied at great length, all the documents gathered together, all notes taken, something more is necessary to get down to the work of composition itself: an effort, often painful, immediately to place oneself in the very heart of the subject and to seek as deeply as possible an impulsion which, as soon as found, carries one forward of itself. This impulsion, once received, sets the mind off on a road where it finds both the information it had gathered and other details as well...yet if one turns around suddenly to seize the impulsion felt, it slips away; for it was not a thing but an urge to movement, and although infinitely extensible, it is simplicity itself. ${ }^{11}$

So as Bergson suggests, intuition is the movement of being absorbed in the duration of time, and often this absorption is facilitated, as the quote suggests, through actively taking up the world. ${ }^{12}$ In this way work becomes a kind of kindling that sparks engagement and enables one to proceed with focus, complementing intellectual understandings with the intuitive. In design this sort of disposition allows one to revel in the act of making, suspending the burdens of knowing what it means, worrying about what is next, or "making it correct." All this can be evaluated when the time is right (Fig. 2).

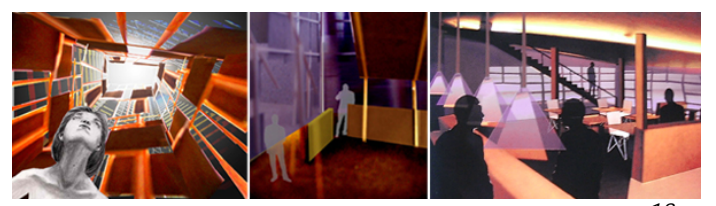

Figure 2: Developing mood into a café. ${ }^{13}$

For intuition to function, the time for evaluation occurs after the intuitive work is complete. This cyclic movement allows the intuitive to be intuitive and the intellectual to be intellectual in what Heidegger has called the hermeneutic circle. This phenomenon shows the paradox of the creative process in that this pair of opposites transcends binary opposition through the movement of a work becoming. This process is carried out as a listening response and despite Bergson's claims of the simplicity of intuition, allowing the intuitive to inform a project is not always quite so easy which is why we will now proceed to look at its mechanisms with some scrutiny.

\section{The Obstacles to I ntuition}

It is interesting that the surrender to the intuitive often becomes increasingly difficult with the more one knows. This difficulty is encouraged by our basic workings as human beings. Aldous Huxley once said that "...the function of the brain and nervous system and sense organs is in the main eliminative and not productive."14 Bergson has made similar claims about the human predilection toward definition and categorization, arguing that intellect "...instinctively selects in a given situation whatever is like something already known; it seeks this out, in order that it might apply its principle that 'like produces like."'15 So we are, by our evolution, trained to assimilate past experiences in order to learn from our encounters and in so doing reduce the need to confront the strangeness of the world. This ability certainly serves us in our daily activities of crossing streets, cooking food, communicating with others, and so on, however, despite all of the obvious benefits, this remarkable capacity for assimilating knowledge often clouds our perceptions as well. Maurice Merleau-Ponty explains how these mechanisms can force a skewed dialogue with reality. 
.... when I give a dictionary definition of a table - a horizontal flat surface supported by three or four legs, which can be used for eating off, reading a book on, and so forth - I may feel that I have got, as it were, to the essence of the table... In this example, however, I am not perceiving but rather defining. By contrast, when I perceive a table, I do not withdraw my interest from the particular way it has of performing its function as a table... What interests me is the unique movement from the feet to the table top which resists gravity; this is what makes each table different from the next. No detail is insignificant: the grain, the shape of the feet, the color and age of the wood, as well as the scratches or graffiti, which show that age. The meaning, 'table' will only interest me insofar as it arises out of all the 'details', which embody its present mode of being. ${ }^{16}$

As this passage suggests, it is in fact the specificity that is important in reaching a true understanding of this table, which flies in the face of our predisposition toward definition, generalization, and category. In this way, intellect and habit dim substantive relations with a situation. At stake in this phenomenon is the vitality of our interactions, which is also reliant upon on an acute awareness within particular activities. So the question arises, how does one come to be affected by a situation? Perhaps the simplicity that Bergson alludes to earlier now may shed some light. It seems his notion of simplicity has to do with what Heidegger elucidates in his statement that, "... we do not need first to call or arrange for this situation in which we let things encounter us without mediation. The situation always prevails." ${ }^{17}$ In other words, the situation is simplicity itself in that we need only open ourselves up to it so as to be affected by the significance that is always already present in its peculiarities. This brings up an important point although one part of intuition is the absorbed intimacy of doing, this absorption can become blindly habitual as well. Therefore also critical to a living intuition is the attuned impulsion that opens the moment of action. The interplay of this embodied and absorbed know-how with spontaneous attuned action is illustrated in the following Zen parable:

A Chinese painter was once commissioned to paint the Emperor's favorite goat. The artist asked for the goat, that he might study it. After two years the Emperor, growing impatient, asked for the return of the goat; the artist obliged. Then the Emperor asked about the painting. The artist confessed that he had not yet made one, and taking an ink brush he drew eight nonchalant strokes, creating the most perfect goat in the annals of Chinese painting. ${ }^{18}$

So in this story one can see how the depth of understanding that comes with prolonged exposure occurs though one's internalization of the knowledge. This internalization is fortified through practices of intimacy, which then transform into the embodied knowledge of an expert. This type of knowledge is not reflected upon, memorized, or recollected, rather it must be spontaneously enacted in a skillful response. In this way the goat is not viewed as an object or a collection of properties gathered under the name "goat," it is an experience.

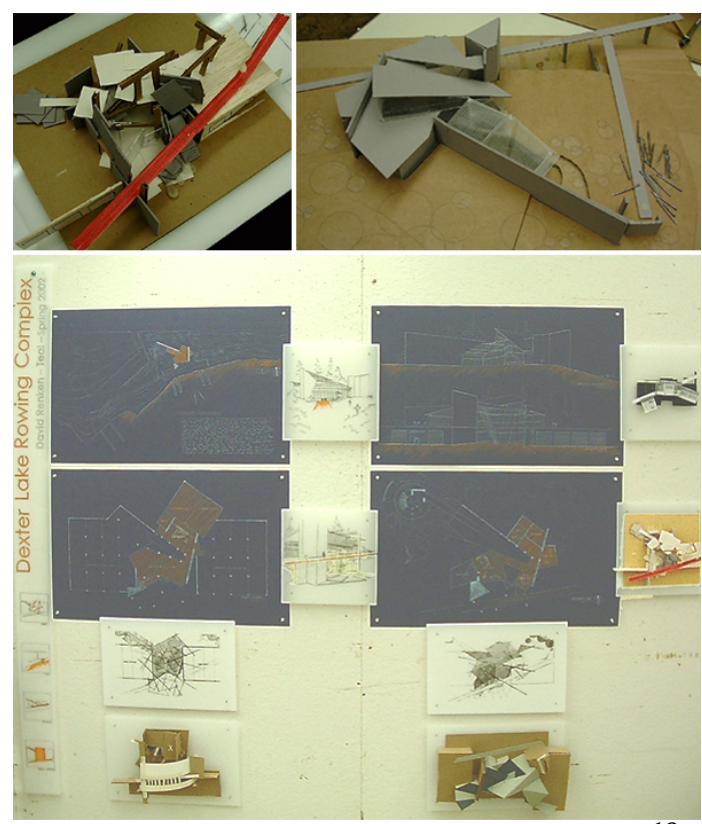

Figure 3: A dialogue with a landscape. ${ }^{19}$

The disposition required for this type of intuitive engagement with situation might be viewed as synonymous with "play." Intuition (like play) in its pure form, does not project results, for the activity itself is reason enough and in some respects training intuition is like reminding people how to play. The goal of this training is to instill an appreciation for forgetting, which is to say a listening. In other words, when intuition is functioning one forgets premade plans and prejudices -- one is the situation. This is 
exactly why intuition is important to design. The involvement that comes with this mode of engagement combats the human propensity for generalization, and affords a designer the receptivity necessary to imbibe the uniqueness of every place and problem, as well as enter into dialogue with their work. Intuitive involvement stands as a corrective to the draw of pure "analysis" which finds itself right in the middle of the intellectual proclivities toward generic description and atomized data collection. Building as object, place as object, language as object-each of these is problematic, as they are fixed and uninhabitable. We necessarily become subjects in this dichotomy. For example, site "analysis" invariably misses the "place," which is why I often ask students to refrain from "explaining" building sites, preferring that they dwell in them. This relation between place and language begins to disclose a peculiar understanding of language -- as something that we are immersed in (Fig 3).

\section{The Language of I ntuition}

"Our relation to language is vague, obscure, almost speechless"20

For Heidegger, language is not an internal tool-kit made of words that one strings together to make meaning, rather it is the coherent significance of situation. Heidegger explains that "communication is never anything like a conveying of experience... from the interior of one subject into the interior of another...discourse is the articulation of intelligibility." ${ }^{21}$ Rather than language being something the human mind adds to inert objects to give them meaning. Heidegger's notion of language is borne out of the implicit relations of one's circumstances. He writes, "what we 'first' hear is never noises or complexes of sounds, but the creaking wagon, the motor-cycle...the fire crackling. It requires a very artificial and complicated frame of mind to 'hear' a 'pure noise'."22 For Heidegger, like Bergson, absorbed concern allows people and things to reveal functions and interrelatedness as freed by our actions. In other words, language lives through our daily activities. In this way specific contexts become vital and thus understood through participation. This participation reveals language and language understood in this way is then a directing towards that which "...already lies before us." ${ }^{23}$ In this statement, Heidegger is saying is that every situation that we encounter is laden with aspects of significance in terms of being of concern to us.
Now this notion of "already before us" should not be taken as a meta-language, or a positivist view of language and this is where the specificity and temporality of situation is critical. Moving within the flow of involvements one realizes that no instant is ever exactly the same - so it is a situational "already-there" that Heidegger suggests. The immersive correspondence between the variability of situation and language is reflected in Heidegger's comment that, "...we are moving within language, which means moving on shifting ground or, still better, on the billowing waters of the ocean." 24 So in directing toward what is already there, one must also be open to the variability of this "there." Variability is the flux that marks both language and situation. In order for one to be able to articulate this "there," one must first develop the capacity to listen and to this end Heidegger reminds us again that, "hearing is constitutive for discourse."25 This comment leads one to the difficult task of response, which might be phrased as hearing and articulating the latent significance (or language) of a situation, remaining sensitive to the inevitable modulations of temporality. Considering the process of design to be a communication, or better a hearing of the "saying" of language ${ }^{26}$ lets us consider how one might activate the language of situation.

If one reflects upon the act of questioning within Heidegger's ideas about language then one understands the question as a particular frame to reveal aspects of a situation. In this way questioning can help to provide direction without creating unnecessary restriction and in turn open up thinking. The link between thinking and questioning is explicated by Heidegger in What is Called Thinking, as he explains that thinking is a kind of discourse that "...clears its own way only by its own questioning advance."27 This advance may be either verbalized or enacted. In architecture, where often the program is seen to be the problem, this notion of questioning is often not employed very effectively. To be fair, the program is a question of sorts but suffers from the same generalities that plague our perceptions. Further the notion of program as question suffers similar problems to those Heidegger sees in the "conventional relation between a sign and its signification,"28 where the Greek notion of sign as a showing turns into a simple determination. Additionally, Heidegger also understands that, "the transformation of the sign from something that shows to something that designates has its roots in the change in the nature of truth." 29 This is to say that as this simplification occurs, a 
richer, more situated understanding of truth is replaced by truth as mere correspondence. The effects of this transformation become the seeds of an inability with living questions. Gilles Deleuze explains how this limitation becomes institutionalized in his book Bergsonism:

...this prejudice goes back to childhood, to the classroom: it is the school teacher who 'poses' the problems; the pupil's task is to discover the solutions. In this way we are kept in a kind of slavery. True freedom lies in a power to decide to constitute problems themselves. ${ }^{30}$

Bergson himself adds an extra incentive for the rediscovery of effective questioning as he explains that "a speculative problem is solved as soon as it is clearly stated." 31 Deleuze elucidates this insight saying, "... the solution exists then, although it may remain hidden and, so to speak, covered up." 32 This is to say that, the question directs us toward the "already-thereness" and in so doing not only establishes that an answer possible but in fact captures the answer within the framework of the question itself.

The value of any question is found in the thought it provokes and the structure it provides for a further "questioning advance," as this opens the doors toward a real understanding of situation and therefore the problem itself. In architecture Louis Kahn, a master of the question, famously realized that the defining problem for the form and the experience of the Kimball Art Museum came from the question of the particular way light would enter the building from a high point, "where the light is best in its zenith." 33 But Kahn is not the only designer to question effectively. Another example of a discursive questioning advance comes from the Viennese firm Propeller $Z$. At the inception of any project, this team of five designers will sit down together and work to draw out the nature of the problem through their discussions before any lines are drawn or models made. It was explained to me that after agreeing as to the fundamental problem, the evolution of their designs always progress very quickly. ${ }^{34}$ The question has also been used less conventionally to provide a structure for response, as can be seen in the work of Steven Holl. In his work, Holl has (famously) used metaphor (seven bottles of light in a stone box - Chapel of St. Ignatius, Fig. 4), music (Music for Strings, Percussion and Celesta by Béla Bartók. - Stretto House) and literature (Basho's poetry-Makuhari Housing Project) to circumscribe problems and their possible solutions.

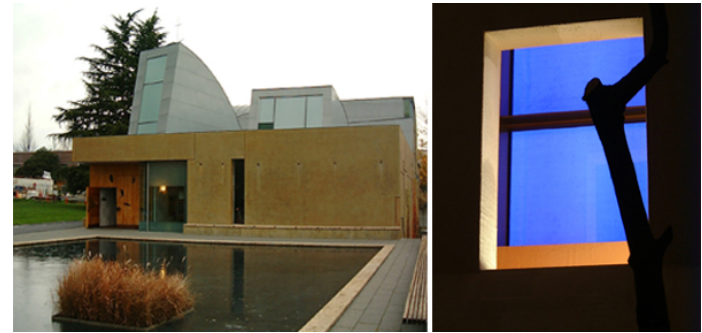

Figure 4: Seven bottles of light in a stone box Chapel of St. Ignatius 35

However, perhaps the least conventional mode of questioning is the most connected to one's intuitive abilities and a Heideggerian notion of language. This occurs when the questions are articulated performatively. For example, Shunyru Suzuki describes that, "a wonderful painting is the result of a feeling in your fingers," and it is in acting on this feeling that ties back into the sort of embodied knowing echoed in earlier notions, and correlates directly to of the "already thereness" of language as Suzuki says, "if you have the feeling of the thickness of the ink in your brush, the painting is already there before you paint. When you dip your brush into the ink you already know the result of your drawing, or else you cannot paint." 36

This is the enactment of language and intuitive knowing may "show" from the work. This is to say, in that it may not be explained outright but it might be felt though the encounter with the finished work itself. With the experience of a work as showing or lighting the work penetrates and communicates intuitively. In this manner it brings Heidegger's "truth."

In reaching this "truth" it is the "...effort, often painful..." that Bergson mentioned previously, which is necessary for showing and becomes the threshold that one must perpetually overcome. The Zen tradition says of this overcoming that "this is the hard part. Technique, though important, is useless without it..."37 As opposed to the subject-oriented or agent-centric notions that one must first be cognitive of intent before proceeding in action, understanding language as a kind of environment that one dwells within means that to enact language one must move and correct as the dialogue unfolds. This type of formal indication is especially effective in complex problems, ones that do not ask for the purity of a singular response or whose answers are too far away too seen from current perspectives. For example in asking students to "build a 
piece of music," students enact a "responding that listens" so as to dwell within the complexities of, say, Ornette Coleman's "Free Jazz" (Fig. 5). In solving this problem, intellect would ask that one stand outside and attempt to define the piece, then to contemplate it as a form, whereas intuition wants to practice being in the experience and work it out through action. In this way the dwelling-in of intuition touches the fundamental ground of language.

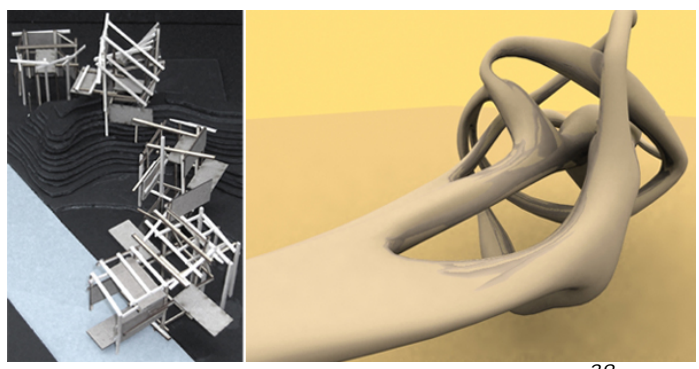

Figure 5: Musical hermeneutics. ${ }^{38}$

This type of a problem is given in studio not to suggest that we need outside inspirations in order to make architecture, but rather to introduce a problem in all of its strangeness, in the case of music one that envelops you. This is done to introduce and practice the complimentary facility of intuition. Put another way, most people will say that they "know" what a house or school, etc. is but will be confounded by the task of building "Free Jazz." This sort of confrontation teaches one the value of knowledge gained through involvement, and no matter what the problem this aspect of knowing is critical to a response correlate to complexities of the problem itself. In attempting to teach lessons about the complexity of any architectural problem and the necessity for understanding the oscillations of the design hermeneutic, these types of inscrutable problems provide training for seeing and engaging similar complexities whether it be designing a library, backyard deck, glazing detail, etc., and allowing the intuitive to fully enter the process. The sophistication of response that rises out of inhabiting the problem begins to show how this faculty of intuition allows a living of language and acknowledges that, "we are, then, within language and with language before all else."39 And even when language is un-verbalized it still speaks to us through the, "...soundless gathering call... we call the ringing of stillness." 40 Language is always calling to us - it is up to us to allow it its full resonance by responding.

\section{The Future for I ntuition}

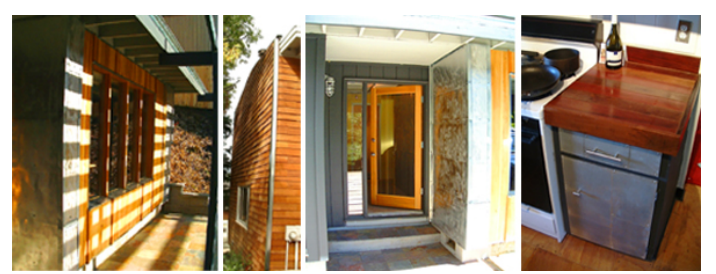

Figure 6: Improvising with materials at full scale. $^{41}$

As Bergson says that, "... our mind has the irresistible tendency to consider the idea it most frequently uses to be the clearest," 42 and so it is therefore important to compliment the tendencies of mind through the sensitive involvement of intuition. This paper is certainly not meant repudiate intellect or suggest its processes and insights inconsequential but rather to situate intellect within the larger domain of the hermeneutic circle where it has as equal partner intuition.

With all the requirements of a building, it can sometimes be easy to miss the fact that measurable things alone will not serve to make it architecture; architecture will be found in cracks between the finite elements - the interrelations. Martin Heidegger tried to show this throughout his life, and that the traditional philosophic problem of the isolated subject that attempts to transcend their own subjectivity in order to experience the world is in fact a false barrier created by the intellect. This derivative state of detached reflection takes us away from our more fundamental situated involvements, being amidst those people and things that concern us. This line of thought is of particular interest to a discipline that needs to be aware of environmental wholeness and situational specificity.

This notion of intuition and the enacting of language are employed in teaching design as a means to dispel notions among students that one should wait for the 'right' inspiration, after which the building will design itself. In this misconception what is not understood is that immersion in work can create inspiration. So even with the example of Propeller Z, who will not initially produce tangible evidence of their work, their discourse is still an active generator of inspiration and a movement forward against the inertia of rumination as that "...effort, often painful..." This is power of the "questioning advance" which may be activated, propelled, and hopefully ingrained through becoming 
familiar with one's ability to listen and respond through the actions of design and making.

A significant aspect of initiating and maintaining this type of awareness is developing comfort with ambiguity, since the genuineness of intuition is to be found in its silence. Notions like "right, "whole," "true," explain what Bergson conceives of when he speaks of the understandings of intuition and it is exactly its whispered tones that make intuition difficult to work with. As Heidegger says in an early lecture at Freiburg, "what develops unity is not an external framework of classification...but the how of the respective understanding insofar as it has a direction which is decisive for each step along the way." 43 And so it is that one might proceed through intuition with each step simply counting as right for its "rightness" alone. If one begins to categorize one begins to generalize and define, and in turn closes off the conversation of intuition. Intuitive interactions with situation are the ways in which one initiates an ability to, "... live in the speaking of language." 44

The goal of this line thinking in design pedagogy is to train a familiarity with the sensations of intuition and establish a means of employing intuition of one's own accord. Ultimately one might not choose to produce collage, spontaneous drawings, or musical structures but the idea is that a facility with this attuned state of working can be carried over into any aspect of the work one does, be it AutoCAD drawings, site visits, or even client meetings (Fig. 6). It is again the immersive living through a problem that releases its finer shades. Intuition compliments the intellect by empowering response, and response infuses the language of humanity into one's work-making it intelligible, making it emotional, and in many cases making it right.

\section{End Notes}

\footnotetext{
${ }^{1}$ Karsten Harries, Infinity and Perspective (Cambridge: MIT Press, 2001) 57.

${ }^{2}$ Martin Heidegger, "Language," in Poetry, Language, Thought (New York: Harper \& Row, 1971), 206.

${ }^{3}$ Martin Heidegger, "The Way to Language," in On the Way to Language (New York: Harper One, 1971), 135.

${ }^{4}$ Martin Heidegger, "A Dialogue on Language," in On the Way to Language (New York: Harper One, 1971), 50.

${ }^{5}$ Gilles Deleuze, Bergsonism (New York: Zone Books, 1991) 115.

${ }_{7}^{6}$ Henri Bergson, "Introduction to Metaphysics," in The Creative Mind (New York: The Philosophical Library, 1946$), 222$.

${ }^{7}$ Ibid., 187.

${ }^{8}$ This montage, which shows two paintings by the author (top row) followed by two rows of student work, aims first to show the author's personal experiences in engaging mood and movement without reflective analysis, and second, to reveal how these experiences are brought to students to help them tread on the same difficult ground. The students responsible for the works are: (row 2, left to right) $1^{\text {st }}$ year students at the University of Oregon - Ashley Smith 2000, Mary Beth Boyd 2002, Marcel Montoya 2000. (row 3, left to right) $2^{\text {nd }}$ year students at the University of Idaho - Norman Wall 2006, Stacy Dobbins 2006.

${ }^{9}$ Martin Heidegger, "The Origin of the Work of Art," in Poetry, Language, Thought (New York: Harper \& Row, 1971$), 25$.

${ }^{10}$ Ibid.

${ }_{11}^{11}$ Bergson, "Introduction to Metaphysics," 235.

${ }^{12}$ This thought also finds resonance with Zen practice, where one is meditatively engaged simply by doing the task at hand as Thich Nhat Hahn states, "I wash the dishes to wash the dishes."

${ }^{13}$ Shannon Haigh, "Café and Cinema," 2004. This was a second-year project at the University of Oregon in which students made a series of quick response models, then developed these in part by turning aspects of the models into Photoshop collages with the idea of slowly evolving the basic feelings of space and place they had discovered before they were making "buildings" and begin to inhabit them as a means of guiding this evolution.

${ }_{14}$ Aldous Huxley, The Doors of Perception, and Heaven and Hell (New York: Haper \& Row, 1954) 22.

${ }^{15}$ Bergson, "Introduction to Metaphysics," 34.

${ }_{16}$ Maurice Merleau-Ponty, The World of Perception (New York: Routledge, 2002) 94.

${ }^{17}$ Heidegger, "The Origin of the Work of Art," 25.

${ }^{18}$ Fredric Lieberman, Zen Buddhism and Its Relationship to Elements of Eastern and Western Arts (June 1997 [cited August 2005]); available from http://arts.ucsc.edu/faculty/lieberman/zen.html.

${ }_{19}$ David Renken, "Boathouse," 2002. This particular student's project, completed during a second-year architecture studio at the University of Oregon, was interesting, as he had images of a boathouse drawn in the first two weeks that were quite realistic. However, his "design" was coming only from him and imposed itself on the distinctive landscape we were working with. I asked the student to back up and try to respond spatially, tectonically, and programmatically to the topography and other features of this place. Further, I challenged him to use the process of making to help reveal aspects of the site. Represented in the images is much of his process. He made a series of loose and exploratory models as a means of learning and ultimately building the site. The model at the top left was a key process model; the model at the top right is his final project, which is also displayed in his final layout below the two other images.

${ }^{20}$ Martin Heidegger, "The Nature of Language," in On the Way to Language (New York: Harper One, 1971), 58.
} 
${ }^{21}$ Martin Heidegger, Being and Time, trans. John Macquarrie and Edward Robinson, Seventh ed. (San Francisco: Harper and Row, 1962) 203-05.

${ }^{22}$ Ibid. 207.

${ }^{23}$ Martin Heidegger, What Is Called Thinking?, trans. J. Glenn Gray (New York: Harper \& Row, 1968) 205.

${ }^{24}$ Ibid. 192.

${ }^{25}$ Heidegger, Being and Time 206.

${ }^{26}$ Heidegger, "A Dialogue on Language," 47.

${ }^{27}$ Heidegger, What Is Called Thinking? 170.

${ }^{28}$ Heidegger, "The Way to Language," 115.

${ }^{29}$ Ibid.

${ }^{30}$ Deleuze, Bergsonism 15.

31 Bergson, "Introduction to Metaphysics," 58.

${ }^{32}$ Deleuze, Bergsonism 15.

${ }^{33}$ Kimbell Art Museum: Award Winning Building, (2000 [cited August 2005]); available from http://www.kimbellart.org/building/Architecture_main3.cfm?id=5.

${ }^{34}$ I visited their offices and spoke to one of the partners, Kabru, during the summer of 2004

${ }^{35}$ Steven Holl. "Chapel of St. Ignatius," Seattle University, Seattle, WA 1997. Photos by Randall Teal 2003.

${ }^{36}$ Shunryu Suzuki, Zen Mind, Beginner's Mind (New York and Tokyo: Weatherhill, 1970) 106.

${ }^{37}$ Lieberman, Zen Buddhism and Its Relationship to Elements of Eastern and Western Arts ([cited).

${ }^{38}$ These two projects were both responses to music. The photo on the left shows a second-year architecture studio project at the University of Idaho, where students were asked to design four follies, with each folly to embody a different jazz song. This particular project was done by Chris Stevens, 2008. The project displayed in the photo on the right was part of independent study undertaken at the University of Oregon. The student, Doug Klassen, wanted to investigate the possibilities for the computer as an intuitive tool. He designed this piece from the music of Thomas Tallis using 3D Studio Max, 2004.

${ }_{39}$ Heidegger, "The Way to Language," 112.

${ }^{40}$ Heidegger, "The Nature of Language," 108.

${ }^{41}$ The images show a comprehensive remodel executed by the author. Each image represents a different phase of the remodel, which took five years to complete. There was no overall plan, and much of what is shown is reclaimed or surplus material. This project developed for the most part by responding to its available resources and building upon moves already made.

${ }^{42}$ Bergson, "Introduction to Metaphysics," 213.

${ }^{43}$ Martin Heidegger, Ontology: The Hermeneutics of Facticity, trans. John Van Buren (Bloomington: Indiana University Press 1999) 35.

${ }^{44}$ Heidegger, "Language," 207.

\section{Bibliography}

Bergson, Henri. "Introduction to Metaphysics." In The Creative Mind. New York: The Philosophical Library, 1946.

Deleuze, Gilles. Bergsonism. New York: Zone Books, 1991.

Harries, Karsten. Infinity and Perspective. Cambridge: MIT Press, 2001.

Heidegger, Martin. Being and Time. Translated by John Macquarrie and Edward Robinson. Seventh ed. San Francisco: Harper and Row, 1962.

"A Dialogue on Language." In On the Way to Language, 57-110. New York: Harper One, 1971.

"Language." In Poetry, Language, Thought, 188-208. New York: Harper \& Row, 1971.

"The Nature of Language." In On the Way to Language, 57-110. New York: Harper One, 1971.

Ontology: The Hermeneutics of Facticity. Translated by John Van Buren. Bloomington: Indiana University Press 1999.

"The Origin of the Work of Art." In Poetry, Language, Thought, 17-79. New York: Harper \& Row, 1971.

"The Way to Language." In On the Way to Language, 57-110. New York: Harper One, 1971.

What Is Called Thinking? Translated by J. Glenn Gray. New York: Harper \& Row, 1968.

Huxley, Aldous. The Doors of Perception, and Heaven and Hell New York: Haper \& Row, 1954.

Kimbell Art Museum: Award Winning Building. 2000 [cited August 2005]. Available from http://www.kimbellart.org/building/Architecture main3.cfm?id=5.

Lieberman, Fredric. Zen Buddhism and Its Relationship to Elements of Eastern and Western Arts June 1997 [cited August 2005]. Available from http://arts.ucsc.edu/faculty/lieberman/zen.html.

Merleau-Ponty, Maurice. The World of Perception. New York: Routledge, 2002.

Suzuki, Shunryu. Zen Mind, Beginner's Mind New York and Tokyo: Weatherhill, 1970. 